\title{
Impact of Caregiver's Psychological Aspects towards Quality of Life of Children with Acute Lymphoblastic Leukemia (ALL)
}

\author{
Irwanto*, Mia Ratwita, Rendi Aji Prihaningtyas, Muhammad Rizki Darmawan \\ Mustakim
}

\begin{abstract}
Background: Families who have children with Acute Lymphoblastic Leukemia (ALL) are at high risk of experiencing stress. Stress on the family can cause the formation of negative communication in children so that families tend to spend more time in dealing with negative emotions through negative actions. This study aimed to analyze the correlation between stress, anxiety, and depression in caregiver with pediatric ALL outcome. Methods: A cross sectional study was conducted on children with ALL and their caregivers at the Pediatric Ward, Dr. Soetomo Hospital, Surabaya. Beck Anxiety Inventory (BAI) and Beck Depression Inventory (BDI) questionnaire were used to measure anxiety and depression in caregivers. Previous stressful experiences in children and caregivers were assessed by The Perceived Stress Scale (PSS), Children quality of life was assessed by pediatric quality of life inventory (PedsQL ${ }^{\mathrm{TM}}$ ) questionnaire. Pearson and Spearman correlation strength test was performed for the statistical analysis. Results: There is no significant correlation between stress level of caregivers with the quality of life of children with ALL ( $P>0.05)$. There is negative correlation between the level of anxiety and depression in caregivers with the quality of life of children $(\mathrm{P}<0.05)$. There is negative correlation between children stress level with the quality of life of children $(\mathrm{P}<0.05)$. Conclusion: The psychological condition of the caregiver affects the quality of life of children. The higher the level of anxiety and depression in caregivers, the lower the quality of life of children.
\end{abstract}

Keywords: ALL- children- stress- anxiety- depression- quality of life

Asian Pac J Cancer Prev, 21 (9), 2683-2688

\section{Introduction}

Interaction between children with ALL and their caregiver is a peculiar phenomenon. Families who have children with cancer are at high risk of experiencing psychological stress (Patiño-Fernández et al., 2008). The level of caregiver stress is known to affect the pattern of caregiver's communication with children with cancer (Rodriguez et al., 2012). Studies have shown that in highly severe or chronic disease, children caregiver tends to have poorer quality of life and higher stress level (Litzelman et al., 2011; Feeley et al., 2014; Nieuwesteeg et al., 2016). Psychological stress on the family can cause the formation of negative communication in children so that families tend to spend more time dealing with negative emotions through negative actions (Murphy et al., 2017). A study even considers such disease as "family problem" rather than child's own problem, and furthermore, caregiver may see the child as a "discomfort" (Nieuwesteeg et al., 2016).

Under chronic exposure of stress, depression and anxiety may exist as a perceived form of psychological status caused by response towards stress. Study reported that although a person may achieve higher education and economical status, susceptibility towards depression and anxiety still lingers and its prevalence is even shown to be increasing alarmingly (Mirzaei et al., 2019). Stress level is known to be higher in caregivers of children with severe, potentially terminal diseases (Feeley et al., 2013; Nieuwesteeg et al., 2016). Meanwhile, based on pediatric quality of life inventory (PedsQLTM) score assessment, children with cancer suffer from worse quality of life compared to normal children (Hilda et al., 2015). Other study may yield good quality of life result for children with cancer, however this is also associated longer period of being dependent on familial support, the isolation from peer groups and the longer way to become independent when the cancer present at younger age (Calaminus et al., 2000). Based on knowledge where caregiver may see a chronically ill child as a "discomfort" under their disease severity (Nieuwesteeg et al., 2016), it is feared that caregiver perceived level of stress, anxiety, and depression may further affect children with cancer's quality of life, creating a vicious ring between both sides' mental status. Screening of psychological problems in 
children with ALL needs to be done (Khalifa et al., 2014). However, understandings between caregiver stress level and children-with-ALL's quality of life is still largely unexplored. Hence, this study aimed to investigate the correlation between caregiver stress levels, anxiety, depression, and child stress level, and children-with-ALL's quality of life.

\section{Materials and Methods}

\section{Study Design}

A cross sectional study was conducted on children aged 10-17 years with ALL and their caregivers in Pediatric Ward of Dr. Soetomo General Hospital, Surabaya, Indonesia, from March to September 2019. This study attempted to identify of psychological status and problems in both caregivers and children with ALL, in the form of stress level, anxiety, stress level, and quality of life. This study aims to analyze the relationship of stress, anxiety, and depression in caregivers with quality of life of children with ALL. The study protocol was approved by the Research and Development Deputy of Dr. Soetomo Hospital. Moreover, the ethical clearance was issued by the Ethical Committee of Dr. Soetomo Hospital (No. 1289/ KEPK/VII/2019).

\section{Study Participants}

Participants in this study must follow the inclusion criteria for both children and their caregivers. The children must be aged 10-17 years, diagnosed with new ALL or relapse at least a month prior to this study, no sensory impairments or neurological deficits, and have caregivers who care for children with ALL for at least 6 months. Informed consent for participation with this study is also an inclusion criterion. Exclusion criteria in this study were cognitive impairment in children and caregivers, and refusal to sign informed consent.

\section{Assessment of the Psychological Aspects and Quality of} Life of Participants

Information about the occurrence of anxiety, stress, and depression in caregivers and their correlation with the quality of life of children with ALL is collected with instruments that correspond with the following symptoms. Anxiety and depression symptoms were assessed subsequently with Beck Anxiety Inventory (BAI) and Beck Depression Inventory (BDI) questionnaire. BDI consists of 21 items. Respondents were asked to assess their own symptoms by using 4 ordinal numbers, which corresponds on the severity of symptoms. The cut-off used was 0-9 for normal ranges, 10-18 for mild-moderate depression, 19-29 for moderate-severe depression, and 30-63 for severe depression (Beck et al., 1988; Beck et al., 1997).

Assessment of previous stress experiences in children and their caregivers was carried out by using The Perceived Stress Scale (PSS), which consisted of ten items scaled by Likert scale. Cut-off score of 0-13 indicates a low stress level, 14-26 indicates a moderate stress level, and 27-40 indicates a severe stress level (Cohen et al., 1983).

Pediatric quality of life is a subjective perception of satisfaction or happiness in life consisting of physical, psychological, and social domains. In this study, pediatric quality of life was assessed using the pediatric quality of life inventory (PedsQL ${ }^{\mathrm{TM}}$ ). The questionnaire consists of 4 assessment functions covering psychological, emotional, social and school functions (Varni et al., 1999).

\section{Statistical Analysis}

Descriptive analysis was carried out using statistical measures (mean, standard deviation, and frequency distribution table). Normality test was carried out by using Saphiro-Wilk test. Spearman's correlation was used for data analysis that is not normally distributed. Pearson correlation strength test was used for the analysis of normally distributed data. If the data is not distributed normally, Spearman correlation strength test was used. Result is considered significant under $\mathrm{P}<0.05$ Data analysis was performed using IBM SPSS ver. 22.0.

\section{Results}

\section{Demographic Characteristics}

A total of 40 caregivers and 40 children with ALL were enrolled in this study. Women dominates the total number of caregivers at 30 persons (75\%). Among those number, $62.5 \%$ are unemployed and gain their income from various external resources. In this study it was found that most of caregivers $(65 \%)$ experienced moderate stress. Most of children $(65 \%)$ also experience moderate stress. In this study it was found that majority of caregivers $(85 \%)$ experienced low level of anxiety, while only small number of caregivers $(2.5 \%)$ experienced high anxiety and minor number of caregivers $(12.5 \%)$ experienced moderate anxiety. Most of the caregivers (42.5\%) did not experience depression, however there is a small number $(5 \%)$ who experienced severe depression. Characteristics of the children and their caregivers were summarized in table 1.

Quality of Life and Psychological Aspects of Participants Prior to further statistical analysis, normality test using Saphiro-Wilk test showed that both the Beck Anxiety Inventory and Beck Depression Inventory scores were not normally distributed $(\mathrm{P}<0.05)$. The cause can be seen in the summary of score distribution, which show tendency towards more normal level of anxiety and depression in both groups.

Results of quality of life assessment using PedsQL ${ }^{\mathrm{TM}}$ indicates that children with ALL suffered from lower quality of life. Caregiver reported that school functioning in children with ALL is the most affected domain, with average scale of 52,42 $\pm 19,95$ (Mean \pm SD). From the assessment of both groups, it showed social functioning is the domain least affected by the disease, with average scale of 81 and very similar standard deviation (16.53 vs 18.19). Summary of PedsQL ${ }^{\mathrm{TM}}$ result is presented in Table 2.

In this study we found significant relationship between anxiety and depression in caregivers with the quality of life of children with ALL $(\mathrm{P}<0.05)$. There was a negative correlation between the level of anxiety and depression in caregivers with the quality of life of children $(r=-0.342$ and $r=-0.033$ respectively). These 
Table 1. Demographic Characteristics of Study

\begin{tabular}{|c|c|c|}
\hline Variable & $\begin{array}{c}\text { Caregiver } \\
\mathrm{N}(\%)\end{array}$ & $\begin{array}{l}\text { Child } \\
\text { N (\%) }\end{array}$ \\
\hline \multicolumn{3}{|l|}{ Caregiver Status } \\
\hline Parents & $35(87.5)$ & \\
\hline Non-parents & $5(12.5)$ & \\
\hline \multicolumn{3}{|l|}{ Sex } \\
\hline Male & $10(25)$ & $22(55)$ \\
\hline Female & $30(75)$ & $18(45)$ \\
\hline \multicolumn{3}{|l|}{ Age } \\
\hline 18-29 years old & $6(15)$ & \\
\hline 30-39 years old & $14(35)$ & \\
\hline 40-49 years old & $13(32.5)$ & \\
\hline$\geq 50$ years old & $7(17.5)$ & \\
\hline \multicolumn{3}{|l|}{ Education Level } \\
\hline Elementary School & $13(32.5)$ & \\
\hline Junior High School & $10(25)$ & \\
\hline Senior High School & $15(37.5)$ & \\
\hline University and higher & $2(5)$ & \\
\hline \multicolumn{3}{|l|}{ Maternal Employment } \\
\hline Employed & $15(37.5)$ & \\
\hline Unemployed & $25(62.5)$ & \\
\hline \multicolumn{3}{|l|}{ Paternal Employment } \\
\hline Employed & $32(80)$ & \\
\hline Unemployed & $8(20)$ & \\
\hline \multicolumn{3}{|l|}{ Perceived Stress Level } \\
\hline High & $7(17.5)$ & $3(7.5)$ \\
\hline Moderate & $26(65)$ & $26(65)$ \\
\hline Low & $7(17.5)$ & $11(27.5)$ \\
\hline \multicolumn{3}{|l|}{ Anxiety Level } \\
\hline High & $1(2.5)$ & \\
\hline Moderate & $5(12.5)$ & \\
\hline Low & $34(85)$ & \\
\hline \multicolumn{3}{|l|}{ Depression Level } \\
\hline Severe & $2(5)$ & \\
\hline Moderate-Severe & $11(27.5)$ & \\
\hline Mild-Moderate & $10(25)$ & \\
\hline Normal & $17(42.5)$ & \\
\hline
\end{tabular}

Table 2. Pediatrics Quality of Life as Assessed by PedsQL ${ }^{\text {TM }}$

\begin{tabular}{lcc}
\hline Domain & \multicolumn{2}{c}{ PedsQL ${ }^{\mathrm{TM}}$ Scale } \\
& $\begin{array}{c}\text { Caregiver-proxy report } \\
\text { (mean } \pm \mathrm{SD} \text { ) }\end{array}$ & $\begin{array}{c}\text { Child-self report } \\
\text { (mean } \pm \mathrm{SD} \text { ) }\end{array}$ \\
\hline Physical Health & $61.02 \pm 21.89$ & $60.77 \pm 27.12$ \\
Psychosocial Health & & \\
$\quad$ Emotional functioning & $60.37 \pm 23.57$ & $61.00 \pm 24.26$ \\
Social functioning & $81.00 \pm 16.53$ & $81.00 \pm 18.19$ \\
School functioning & $52.42 \pm 19.95$ & $64.00 \pm 18.29$ \\
\hline
\end{tabular}

*Quality of life based on 0-100 scales, which is the reversed and transformed scale based on reported score. Higher score indicates better health-related quality of life.

findings are summarized in Table 3.

In this study we found no significant relationship between stress on caregivers and children with the quality of life of children with ALL (P > 0.05). However, we found correlation between children's level of stress and their quality of life $(\mathrm{P}<0.05)$. The higher the level of stress in the child, the lower the child's quality of life (r $=-0,076)$. It is important to note that in this study, when PedsQL ${ }^{\mathrm{TM}}$ examination was carried out by the child, it is more likely for them to report stress level inequal to those reported by their caregiver. Because of this, we did not find any correlation between caregiver level of anxiety and depression with children quality of life when the PedsQL ${ }^{\mathrm{TM}}$ is carried out by the children. The only correlation when a child reported their PedsQL ${ }^{\mathrm{TM}}$ result is with their perceived stress level $(\mathrm{P}<0.05, \mathrm{r}=-0.401)$. These findings are summarized in Table 3.

\section{Discussion}

Cancer diagnosis and treatment in children may cause psychological problems in children and their families, which further affect the quality of life of children (Rodriguez et al., 2012). Child cancer treatment is known to cause psychological burden for caregivers, whether it is during or post-treatment (Hutchinson et al., 2009). Anxiety and depression screening in children with chronic diseases needs to be done (Abo Amer et al., 2013). These factors combined by sociodemographic conditions can further trigger increased stress in children with cancer (Bemis et al., 2015). Stress assessment can be done in various ways,

Table 3. Correlation between Caregiver's Beck Anxiety Inventory, Perceived Stress Scale, and Beck Depression Inventory Score with PedsQL

\begin{tabular}{lccc}
\hline Instrument & & $\begin{array}{c}\text { PedsQL } \\
\text { (caregiver-proxy report) }\end{array}$ & $\begin{array}{c}\text { PedsQL }^{\mathrm{TM}} \\
\text { (child-self report) }\end{array}$ \\
\hline Beck Anxiety Inventory Score of Caregiver & $\mathrm{P}$ & $0.031^{*}$ & 0.663 \\
Beck Depression Inventory Score of Caregiver & $\sigma$ & -0.342 & 0.071 \\
Perceived Stress Scale Score of Children & $\mathrm{P}$ & $0.033^{*}$ & 0,331 \\
& $\sigma$ & -0.033 & -0.015 \\
Perceived Stress Scale Score of Caregiver & $\mathrm{P}$ & $0.000^{\S}$ & $0.010 \S$ \\
& $\mathrm{r}$ & -0.532 & -0.401 \\
\hline
\end{tabular}

*, Spearman's correlation strength test. Significant under $\mathrm{P}<0.05$; , Pearson correlation strength test. Significant under $\mathrm{P}<0.05$ 
including examining psychological symptoms, assessing stress scales, measuring depression and anxiety levels, assessing mental scales for quality of life, and measuring traumatic stress scale (Sultan et al., 2016).

General studies about caregivers' stress in Indonesian population of family with children suffering ALL are already exists but still relatively scarce. Many of the publications with different team of researchers span about a half-decade between each other, thus stressing that psychological aspects are often neglected in providing holistic leukemia care in Indonesia. Prior to the era of 2015 Indonesian national health insurance program, it was shown that leukemia gives very high socioeconomical impact, as well as psychological distress in the family. Majority of respondents' income are decreased since the start of treatment, while small but significant number of employed parents are losing their jobs because they have to give more care towards the sick children. The high treatment cost cause $65 \%$ of parents to be indebted, which further impacting the compliance to treatment. More importantly, more than half of parents feels that they don't receive social and emotional support from employers and their peers (Mostert et al., 2006; Mostert et al., 2006). The advent of Indonesian national health insurance program in 2015 seemed to relieve this socioeconomic constraint, as showed in a study where all participants were funded by the program and mild average stress level in mothers based on Depression Anxiety Stress Scale 21 (DASS) score (Krisnana et al., 2019). While the former study showed better condition in mother, a recent study showed the opposite in the male side. The study states that older age, male, having a primary education level, caring for their children for less than 12 months with severe leukemia, and having an average monthly income of fewer than IDR 1.5 million (around USD 102.5) have more socioeconomic burden and poorer quality of life (Nurhidayah et al., 2020). These evidences showed that despite of low stress score level measured my valid instruments, psychological burden and poorer quality of life still remains high in the family of children with ALL.

From child health perspective, health quality is an important part of the quality of life in children, which includes physical, mental, and social health. Assessment for quality of life information in children from children and parents needs to be done to improve detection of quality of life disorders in children. PedsQL ${ }^{\text {TM }}$ is one of the most commonly used methods for assessing quality of life in children. A study showed that in children with ALL, the PedsQL score indicates that younger children had more problems in procedural anxiety, treatment anxiety and communication subscales (Sitaresmi et al., 2008). The correlation of PedsQL ${ }^{\mathrm{TM}}$ scores in children and parents is high in children suffering from chronic diseases (Vogels et al., 1998).

Depression and anxiety are the most common mental disorders in children with cancer. Chronic illness may increase the prevalence of depression by $10-20 \%$ in children with cancer compared to healthy children. This condition is a result of a child's vulnerability to depression, disease characteristics, and environmental stressors or negative life events that occur together with chronic illness (Bemis et al., 2015). Risk factors for psychiatric problems in children with ALL, including older age, female sex, and the presence of psychiatric problems in the caregiver (Khalifa et al., 2014). Among the internal family condition, positive mood built in the family is a protective factor against depression in children (Jaser et al., 2011).

In this study it was found that majority of both caregivers and children experienced moderate stress. Emotional problems can occur in parents in the first few months after a child is diagnosed with ALL (Neu et al., 2014). Previous study in Bandung, Indonesia stated that as many $39 \%$ mothers who have children suffering from leukemia experience severe stress and as many $35 \%$ experience moderate behavioral disorders (Wati et al., 2018). The incidence of psychological disorders in children increases with the duration of the illness (Abo Amer et al., 2013). Previous studies shown that symptoms of stress that often occur in parents of children with cancer include anxiety, difficulty concentrating, feelings of guilt, pessimism, sadness, post-traumatic disorders and sleep disorders (Abo Amer et al., 2013). Nearly 60\% of children with ALL suffer from psychiatric disorders (Khalifa et al., 2014). Factors that influence the level of stress in parents of children with cancer can generally be classified into disease severity and its treatment, individual factors, and internal family condition (Sultan et al., 2016). Chemotherapy in ALL can cause psychological disorders in children and caregivers (Sherief et al., 2015).

In this study, we found that the higher level of anxiety and depression in caregivers, the lower quality of life of children is. Children who have cancer may experience physical disabilities, mental disorders, and impaired social function as a result of cancer malignancy and side effects of treatment. Several studies have shown that there are $60 \%$ of children with cancer sufferer's sequel to physical and psychological disorders (Michel et al., 2015). Study in Indonesia stated that the main source of stress experienced came from a family that is the condition of a sick child. Their family suffered from prolonged fear and sadness (Sudarji et al., 2016). Coping abilities and lower levels of depression in caregiver have a correlation with positive communication (Vitorino et al., 2018). By knowing the communication patterns of caregivers and the factors that influence them, more effective communication that may be attempted to improve outcomes in children (Jaser et al., 2011). In family caregiver score, better communication will lead to better support and less conflicts. Greater family support and smaller conflict in the family has been linked to better children's cancer treatment outcomes (Michel et al., 2015).

Previous studies showed that active treatment status in pediatric cancer patients was associated with increased stress, depression, anxiety and post-traumatic stress symptoms (Hutchinson et al., 2009). Individual factors that influence stress on parents of children with cancer include coping abilities in parents (Sultan et al., 2016). Study in Denpasar, Bali showed that Children with ALL who undergo treatment therapy showed coping strategies, 
including accepting responsibility, humor, wishful thinking, assistance seeking, behavioral management, direct action, emotional approach, denial, self-control, and self criticism (Damayanti et al., 2016). Studies showed that the coping skills in caregiver may affect child stress level (Vitorino et al., 2018). In addition, family factors have also been shown to be related to parental stress levels. Studies showed that poor family function as shown by low cohesiveness, family support, and conflict in the family is related to stress and traumatic stress (McCarthyal et al., 2012).

Although we were able to confirm previous findings based on our results, this study still has limitation. Due to the study design, serial data collection was not conducted to assess the psychological condition changes of children and parents. Our study while able to explain the correlation between child and caregiver psychological conditions at one specific time still barely able to tell the long-term effect of both group interaction, especially in an advancing disease condition. Further studies are needed to observe the continual interaction and its psychological outcome between caregiver and child with ALL.

In conclusion, psychological conditions of caregivers may affect the quality of life of children. Children report of stress level is correlated negatively with their quality of life. Higher level of anxiety and depression in caregivers is correlated weakly with lower quality of life of children.

\section{Acknowledgements}

The authors wish to thank the Director of Dr. Soetomo Hospital, Surabaya, Indonesia, for the ethical approval and support in this study. All authors declared no conflict of interest related to financial support or relationships during the proposal writings, data collection, analysis, and manuscript writings of this study. The Ethical Committee of Dr. Soetomo Hospital handled all ethical issues during this study.

Authors contributions were described as in the followings: Irwanto, Mia Ratwita, Rendi Aji Prihaningtyas, and Muhammad Rizki Darmawan Mustakim designed, collected the samples, and conducted the initial analysis. Prihatiningtyas and Mustakim conducted further analysis and did the manuscript writing. All authors did the discussion prior to the decision to publish the manuscript. Finally, Irwanto and Ratwita confirmed the analysis and discussion result, as well as proofread the manuscript. All authors had read and approved the final version this manuscript.

\section{References}

Abo Amer AA, Abdel Maksod YH, El Bakry ST, El-Yamany WHM (2013). Anxiety and depression among children with chronic diseases. Middle East Curr Psychiatry, 20, 146-55.

Beck AT, Epstein N, Brown G, Steer RA (1988). An inventory for measuring clinical anxiety: Psychometric properties. J Consult Clin Psychol, 56, 893-7.

Beck AT, Guth D, Steer RA, Ball R (1997). Screening for major depression disorders in medical inpatients with the Beck depression inventory for primary care. Behav Res Ther, 35, 785-91.
Bemis H, Yarboi J, Gerhardt CA, et al (2015). Childhood Cancer in Context: Sociodemographic Factors, Stress, and Psychological Distress Among Mothers and Children. $J$ Pediatr Psychol, 40, 733-43.

Calaminus G, Weinspach S, Teske C, Göbel U (2000). Quality of life in children and adolescents with cancer. First results of an evaluation of 49 patients with the PEDQOL questionnaire. Klin Padiatr, 212, 211-5.

Cohen S, Kamarck T, Mermelstein R (1983). A global measure of perceived stress. J Health Soc Behav, 24, 385-96.

Damayanti KT, Susilawati LKPA (2016). Gambaran strategi coping anak dengan leukemia limfoblastik akut dalam menjalani terapi pengobatan. Jurnal Psikologi Udayana, 3, 244-60.

Feeley CA, Turner-Henson A, Christian BJ, et al (2014). Sleep quality, stress, caregiver burden, and quality of life in maternal caregivers of young children with bronchopulmonary dysplasia. J Pediatr Nurs, 29, 29-38.

Hilda H, Lubis B, Hakimi H, Siregar OR (2015). Quality of life in children with cancer and their normal siblings. Paediatr Indones, 55, 243.

Hutchinson KC, Willard VW, Hardy KK, Bonner MJ (2009). Adjustment of caregivers of pediatric patients with brain tumors: a cross-sectional analysis. Psychooncology, 18, 515-23.

Jaser SS, Champion JE, Dharamsi KR, Riesing MM, Compas BE (2011). Coping and positive affect in adolescents of mothers with and without a history of depression. J Child Fam Stud, 20, 353-60.

Khalifa AS, Bishry Z, Tantawy AA, et al (2014). Psychiatric morbidity in Egyptian children with acute lymphoblastic leukemia and their care providers. Hematol Oncol Stem Cell Ther, 7, 76-84.

Krisnana I, Sulistyarini H, Rachmawati PD, Arief YS, Kurnia ID (2019). Reducing acute stress disorders in mothers of leukemic children by means of the Family Centered Empowerment module (FACE). Cent Eur J Nurs Midw, 10, 1035-40.

Litzelman K, Catrine K, Gangnon R, Witt WP (2011). Quality of life among parents of children with cancer or brain tumors: the impact of child characteristics and parental psychosocial factors. Qual Life Res, 20, 1261-9.

McCarthy MC, Ashley DM, Lee KJ, Anderson VA (2012). Predictors of acute and posttraumatic stress symptoms in parents following their child's cancer diagnosis. J Trauma Stress, 25, 558-66.

Michel G, Vetsch J (2015). Screening for psychological late effects in childhood, adolescent and young adult cancer survivors: a systematic review. Curr Opin Oncol, 27, 297-305.

Mirzaei M, Yasini Ardekani SM, Mirzaei M, Dehghani A(2019). Prevalence of depression, anxiety and stress among adult population: Results of Yazd Health Study. Iran J Psychiatry, 14, 137-46.

Mostert S, Sitaresmi MN, Gundy CM, Sutaryo, Veerman AJP (2006). Influence of socioeconomic status on childhood acute lymphoblastic leukemia treatment in Indonesia. Pediatrics, 118, e1600-6.

Mostert S, Sitaresmi MN, Gundy CM, Sutaryo, Veerman AJP (2008). Parental experiences of childhood leukemia treatment in Indonesia. Pediatr Hematol Oncol, 30, 738-43.

Murphy LK, Murray CB, Compas BE, et al (2017). Topical review: Integrating findings on direct observation of family communication in studies comparing pediatric chronic Illness and typically developing samples. J Pediatr Psychol, 42, 85-94.

Neu M, Matthews E, King NA, Cook PF, Laudenslager ML 
(2014). Anxiety, depression, stress, and cortisol levels in mothers of children undergoing maintenance therapy for childhood acute lymphoblastic leukemia. J Pediatr Oncol Nurs, 31, 104-13.

Nieuwesteeg AM, Hartman EE, Aanstoot H-J, et al (2016). The relationship between parenting stress and parent-child interaction with health outcomes in the youngest patients with type 1 diabetes (0-7 years). Euro J Pediatr, 175, 329-38.

Nurhidayah I, Hendrawati S, Hasriyadhi DP (2020). Quality of life of family caregivers of children with leukemia: A Descriptive Quantitative Study. Belitung Nurs J, 6, 52-8.

Patiño-Fernández AM, Pai ALH, Alderfer M, et al (2008). Acute stress in parents of children newly diagnosed with cancer. Pediatr Blood Cancer, 50, 289-92.

Rodriguez EM, Dunn MJ, Zuckerman T, et al (2012). Cancerrelated sources of stress for children with cancer and their parents. J Pediatr Psychol, 37, 185-97.

Sherief LM, Kamal NM, Abdalrahman HM, et al (2015). Psychological impact of chemotherapy for childhood acute lymphoblastic leukemia on patients and their parents. Medicine, 94, e2280.

Sitaresmi MN, Mostert S, Gundy CM, Sutaryo, Veerman AJP (2008). Health-related quality of life assessment in Indonesian childhood acute lymphoblastic leukemia. Health Qual Life Outcomes, 6, 96

Sudarji S, Wahono DL (2016). Coping stress pada orang tua anak dengan leukemia limfositik akut (ALL). Psibernetika, 9, 113-24.

Sultan S, Leclair T, Rondeau É, Burns W, Abate C (2016). A systematic review on factors and consequences of parental distress as related to childhood cancer. Eur J Cancer Care, 25, 616-37.

Varni JW, Seid M, Rode CA(1999). The PedsQL ${ }^{\text {TM: }}$ Measurement Model for the Pediatric Quality of Life Inventory. Med Care, 37, 126-39.

Vitorino LM, Lopes-Júnior LC, de Oliveira GH, et al (2018). Spiritual and religious coping and depression among family caregivers of pediatric cancer patients in Latin America. Psychooncology, 27, 1900-7.

Vogels T, Verrips GH, Verloove-Vanhorick SP, et al (1998). Measuring health-related quality of life in children: the development of the TACQOL parent form. Qual Life Res, 7, 457-65.

Wati NL, Qoyyimah DF (2018). Tingkat stres ibu yang mempunyai anak kanker leukemia di Rumah Cinta Bandung. Jurnal Keperawatan BSI, 6, 69-76.

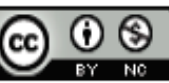

This work is licensed under a Creative Commons AttributionNon Commercial 4.0 International License. 